\title{
Towards increasing health care in the developing world: Development of a sustainable site in Bolivia
}

\author{
Thomas M. Gellhaus, MD ${ }^{1}$ \\ Key Words: developing countries, health services, voluntary workers, sustainable health care, Bolivia, \\ University of lowa
}

\begin{abstract} completed 16 projects in the Dominican Republican, Ecuador, Peru, Bolivia, and Tanzania. In direct response to Dr. Gellhaus's successes, the Department of Obstetrics and Gynecology at the University of lowa has made a commitment to develop a sustainable site in Bolivia. Current plans include annual projects that allow physicians and residents to provide valuable medical care to patients in Bolivia, and the long-term vision is to develop an infrastructure that improves health care in this population.

${ }^{1}$ The Department of Obstetrics and Gynecology, The Carver College of Medicine, The University of lowa, lowa City, lowa, USA
\end{abstract}

Most Americans are aware of the great need for health care services in the developing world. In this article, Dr. Thomas Gellhaus provides a compelling story of his volunteer efforts to provide obstetric/gynecologic surgical services to developing countries. Since 1996, he has

Most Americans are aware of the great need for health care services in the developing world. In a report from the World Health Organization in 2007, the United States had 27 health care providers per 10,000 people, while Bolivia had only 12 health care workers

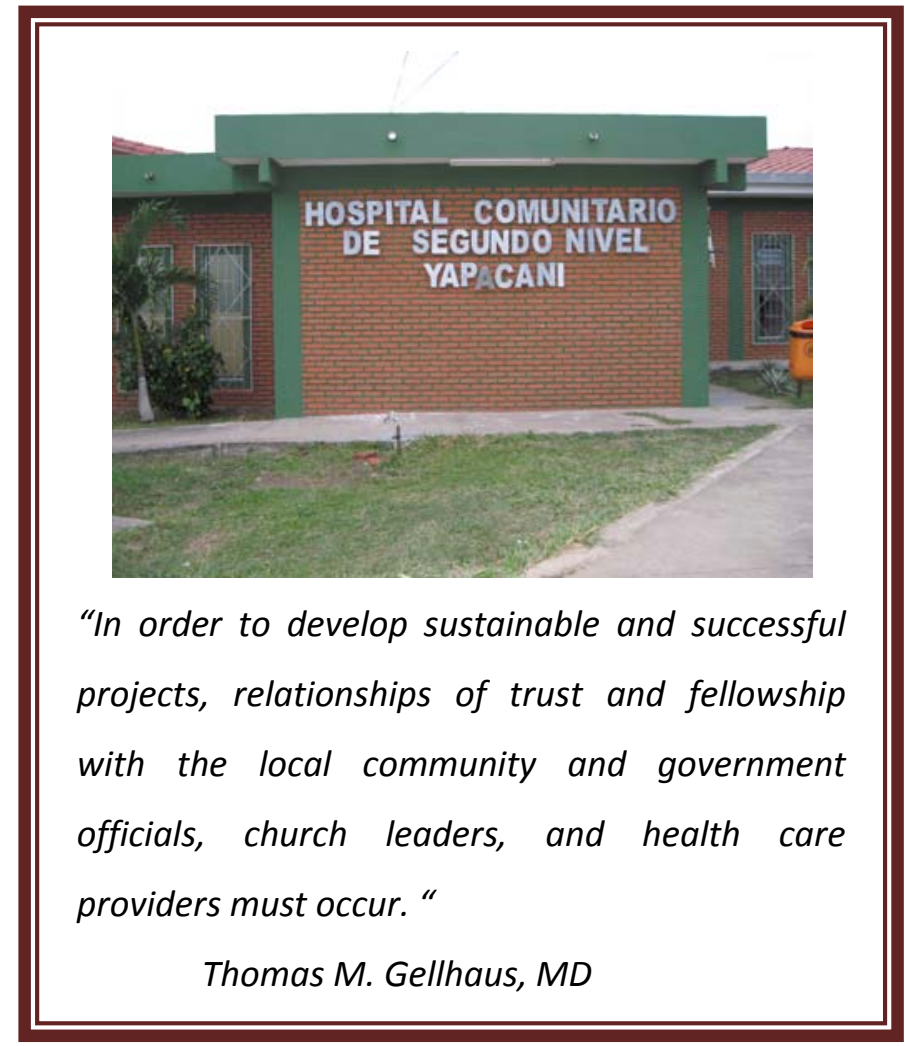

per 10,000 people and

Zambia and Kenya only 1 health care worker per 10,000 people. These staggering and sobering statistics subsequen tly reflect a marked difference in the life expectanc y between the United States and

Please cite this paper as: Gellhaus, TM. Towards increasing health care in the developing world: development of a sustainable site in Bolivia. Proc Obstet Gynecol. 2011 November;2(2):Article 1 [ 3 p.]. Available from: http://ir.uiowa.edu/pog/. Free full text article.

Corresponding author: Thomas M. Gellhaus, M.D. Department of Obstetrics and Gynecology, University of lowa, 51220 PFP, 200 Hawkins Drive, lowa City, IA 52242. Telephone (319)356-7576. thomas-gellhaus@uiowa.edu.

This is an Open Access article distributed under the terms of the Creative Commons Attribution 3.0 Unported License (http://creativecommons.org/licenses/by/3.0), which permits unrestricted use, distribution, and reproduction in any medium, provided the original work is properly cited 
these and other developing world countries. United States citizens live to approximately 76 years of age, whereas in Kenya and Zimbabwe the average life span is only approximately 53 and 42 years of age, respectively.

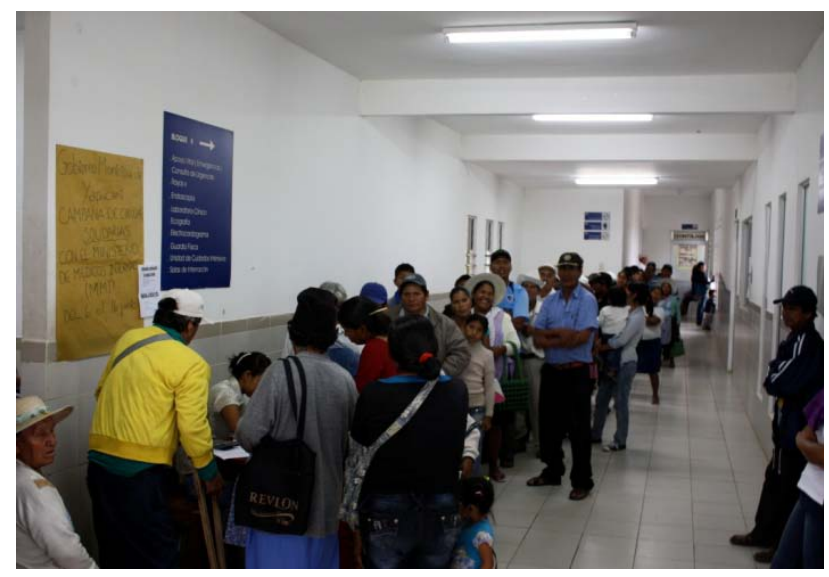

The line for those waiting for medical services begins

Many health care providers in our country have or have had a desire to provide care in developing countries around the world. For many, the obstacles to providing care seem insurmountable. Furthermore, concerns about providing care in low resource areas can be very anxiety provoking and thus inhibit involvement. Prior to 1996, I was one of those providers; however, my life and our family's life changed in 1996. My wife, my then 12-year-old daughter, and I attended a presentation by another physician who had recently participated in a medical mission project in the Dominican Republic. I distinctly remember thinking what he had done was great, yet I was very uncertain of my ability and my desire to do the same. Each evening after returning home, my daughter repeatedly stated and asked during dinner, "We need to do this. When are we going?" Each evening I Increasing health care in the developing world reluctantly replied with the same response, "Yeah, sure, maybe someday." In my mind I was thinking there was no way I could provide gynecologic surgical services in such a low resource setting without the benefits of all the technology available in the United States. Fortunately, there is nothing like the persistence of a 12year-old. Her persistence continued and I ultimately relented by completing and mailing the applications for my wife, my daughter, and me for a short-term two-week mission in the Dominican Republic. I only hoped they would not need us. Shortly after mailing the application forms I received a call from the organization leading these missions who very excitedly stated, "We need you and your services in the worst of ways." I then thought to myself, "What did I get myself into this time?" In June 1996, the three of us traveled to the Dominican Republic and completed our first twoweek medical and surgical mission project, and our family's life and my life have never been the same.

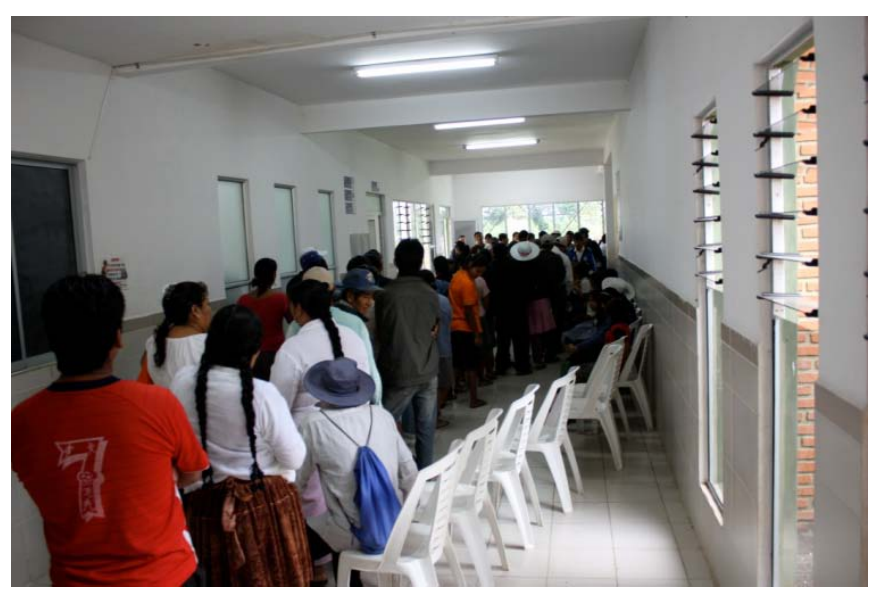

and the line continues around the corner and down the hall. 
Since that first project in 1996, we have completed 16 projects in the Dominican Republican, Ecuador, Peru, Bolivia, and Tanzania. On our project in 1996, we joined another group, but since that time we have been organizing and leading projects that have varied in size from 22 to nearly 90 participants. Over the last 16 years we have had 720 participants, many of whom have returned nearly every year to donate their services. Our medical clinics have seen nearly 18,000 patients and provided over 52,000 filled medication prescriptions. Our surgical teams have completed nearly 1750 major and minor surgical procedures and performed nearly 3400 surgical consultations.

Since joining the Department of Obstetrics and Gynecology at the University of lowa, our chair, Dr. Kimberly Leslie, has enthusiastically supported continuing these efforts in Bolivia. On the most recent project in June 2011, a second year University of lowa Ob/Gyn resident accompanied our group of 23 team members to Yapacani, Bolivia. Under the instruction of three practicing and experienced obstetricians - gynecologists, she was able to participate in multiple gynecologic surgeries during the two weeks in country. Understanding the low number of health care providers in Bolivia and especially in the rural areas where the group worked last summer, the Department of Ob/Gyn at the University of lowa has made a commitment to develop a sustainable site in this area in Bolivia. Current plans include annual projects, which will become more frequent in the future as our infrastructure develops. In order to develop sustainable and successful projects, relationships of trust and fellowship with the local community and government officials, church leaders, and health care providers must occur. Long-term projects require the integration of sustainable technology and educational resources into the local medical community. Over time and as this type of project grows, additional infrastructure may be constructed to further provide an improvement in care within this community.

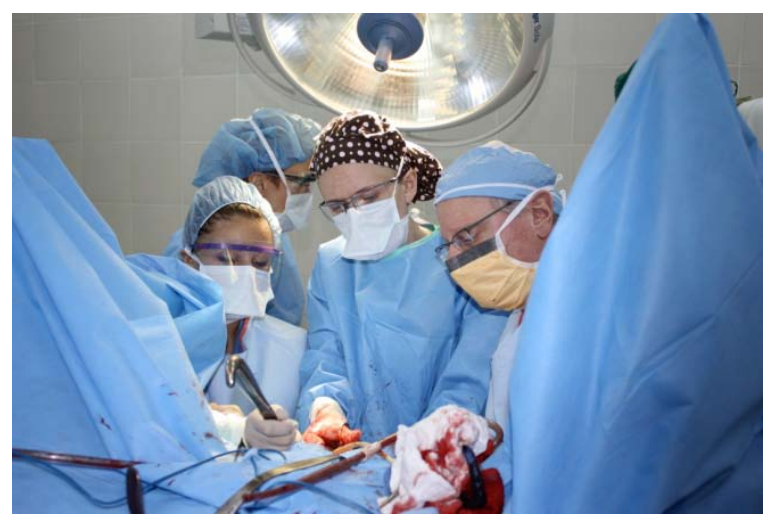

Resident operates alongside veteran surgeon.

In conclusion, surgical volunteerism is possible and can be accomplished without quitting your job and moving your family to the developing world. It always seems that we receive so much more from these projects than the people we serve and so much can and is learned by both parties involved. If not through the ideals of a 12-year-old, listen to your own heart and take a chance. You will never be the same!!

\section{Reference}

${ }^{1}$ World Health Statistics 2007, http://www.who.int/whosis/whostat/2007/en/inde x.html 